\title{
Through Process Modelling of Rolling and Controlled Cooling of TRIP Assisted Bainitic Steel Rods and Prediction of the Retained Austenite in Products
}

\author{
Roman Kuziak ${ }^{1, a^{*}}$, Zofia Kania ${ }^{2, b}$, Valeriy Pidvysots'kyy ${ }^{2 c}$, \\ Hans Roelofs ${ }^{2, \mathrm{~d}}$, Monika Pernach ${ }^{3, \mathrm{e}}$ and Maciej Pietrzyk ${ }^{3, \mathrm{f}}$ \\ ${ }^{1}$ Institute for Ferrous Metallurgy, K. Miarki 12, 44-100 Gliwice, Poland \\ ${ }^{2}$ Swiss Steel, Emmenbrucke, Emmenweidstrasse 90, 6020, Switzerland \\ ${ }^{3} \mathrm{AGH}$ University of Science and Technology, al. Mickiewicza 30, 30-059 Kraków, Poland \\ ${ }^{a}$ RKuziak@imz.pl, 'Kania@imz.pl, 'VPidvysotskyy@imz.pl \\ dHRoelofs@swiss-steel.com, ${ }^{\text {d}}$ Pernach@agh.edu.pl, ${ }^{f}$ Maciej.Pietrzyk@agh.edu.pl
}

\begin{abstract}
Keywords: Rod rolling, controlled cooling, modelling, bainitic steels, phase transformations, retained austenite.
\end{abstract}

\begin{abstract}
Simulation of the rolling and controlled cooling sequence for bainitic steel rods was the general objective of the paper. The main focus was put on exploring possibility of prediction of the retained austenite occurrence in TRIP assisted bainitic steels. Existing discrete phase transformation models require long computing times and their application to optimization of industrial processes is limited. Therefore, a model based on the modified JMAK equation was proposed. The occurrence of the retained austenite was predicted by carbon distribution calculations in the austenite during bainite transformation. This model was implemented into the FE software for simulation of cooling of rods. The model was verified by comparison of results with the physical simulations during rolling in the pilot mill and during cooling. The first part of the paper contains thermal-mechanicalmicrostructural simulations of rod hot rolling process. The objective of this part was to determine temperature and grain size distribution at the rod cross section at the beginning of phase transformations. FE simulations of the cooling were performed next. Correlation between cooling parameters and the volume fraction of the retained austenite in rod was determined.
\end{abstract}

\section{Introduction}

Due to a wide range of mechanical properties, bainitic steels are good candidates for many applications, for example in automobile and power generating industries, as well as in the production of armoured plates with outstanding ballistic properties [1,2]. Premium rails [2,3] or other long products [4] may also be made of bainitic steels. The automobile weight can be reduced by using high-strength steels as long as they maintain the ductility at the required level. The objective of this paper was to investigate a selected bainitic steel behaviour during hot rolling. The emphasis was put on application of numerical modelling to predict microstructure and properties of products.

Fast progress in modelling of metal forming processes encouraged researchers to look for better technologies, which can be done through their design optimization. On the other hand, the efficient and reliable application of modern models combined with iterative optimization techniques is strongly dependent on the correctness of material's behaviour description. Selection of the best models, having in mind their predictive capabilities and computing costs, is crucial in this research [5]. Multi physics models, which combine thermal, mechanical and thermodynamic phenomena, are used to account for the microstructural features of the material. Prediction of microstructure and products properties became an inseparable part of simulations and these parameters are often used in objective functions in process optimization. Therefore, the main objective of the present paper was exploring possibilities of efficient prediction of products microstructure by simulations of the 
whole manufacturing chain. To reach this goal thermal, mechanical and microstructural models were proposed and validated by comparison with the experimental data.

\section{Investigated process}

Rod rolling in the pilot mill was investigated. The material was bainitic steel containing $0.23 \%$ $\mathrm{C}, 1.52 \% \mathrm{Mn}, 0.98 \% \mathrm{Si}, 1.51 \% \mathrm{Cr}$ [wt.\%]. Squared rod measuring $44 \times 800 \mathrm{~mm}$ obtained by hot forging was used as a stock material. The rod was heated before rolling to $1200{ }^{\circ} \mathrm{C}$. Rolling was performed in two passes with parameters given in Table 1 .

Table 1. Parameters of the rod rolling process

\begin{tabular}{|c|c|c|c|c|c|c|}
\hline Pass & $\begin{array}{c}\text { height } \\
{[\mathrm{mm}]}\end{array}$ & $\begin{array}{c}\text { width } \\
{[\mathrm{mm}]}\end{array}$ & $\begin{array}{c}\text { temperature } \\
\text { entry }\left[{ }^{\circ} \mathrm{C}\right]\end{array}$ & $\begin{array}{c}\text { temperature } \\
\text { exit }\left[{ }^{\circ} \mathrm{C}\right]\end{array}$ & $\begin{array}{c}\text { velocity } \\
{[\mathrm{m} / \mathrm{s}]}\end{array}$ & $\begin{array}{c}\text { time } \\
{[\mathrm{s}]}\end{array}$ \\
\hline 0 & 44 & 44 & 1200 & - & - & 43.7 \\
\hline 1 & 32.8 & 45 & 909 & 957 & 0.31 & 4.7 \\
\hline 2 & 38 & 36 & 917 & 914 & 0.32 & 30.9 \\
\hline
\end{tabular}

It was assumed in simulations that the stock material was heated to the uniform temperature of $1200{ }^{\circ} \mathrm{C}$ and the grain size after heating was $90 \mu \mathrm{m}$. Rolling process was divided into 5 steps:

- transport between the furnace and the mill (cooling);

- rolling in the first pass;

- change of the rolling direction and cooling during the interpass time;

- rolling in the second pass;

- cooling in the air.

\section{Models}

Simulation of the whole manufacturing cycle composed of hot rolling and cooling was performed in the paper. Models describing this cycle, including models of rolling parameters, temperatures, microstructure evolution and phase transformations are described briefly in this chapter.

Rolling of rods. The thermal-mechanical finite element (FE) method was used to calculate rolling parameters. The process has two symmetry axes, therefore, a quarter of the cross section was considered. To accelerate calculations rigid rolls were assumed. Positions of rolls in each pass were taken from measurements.

Figure 1 shows the view of the roll and the mesh in the FE model.

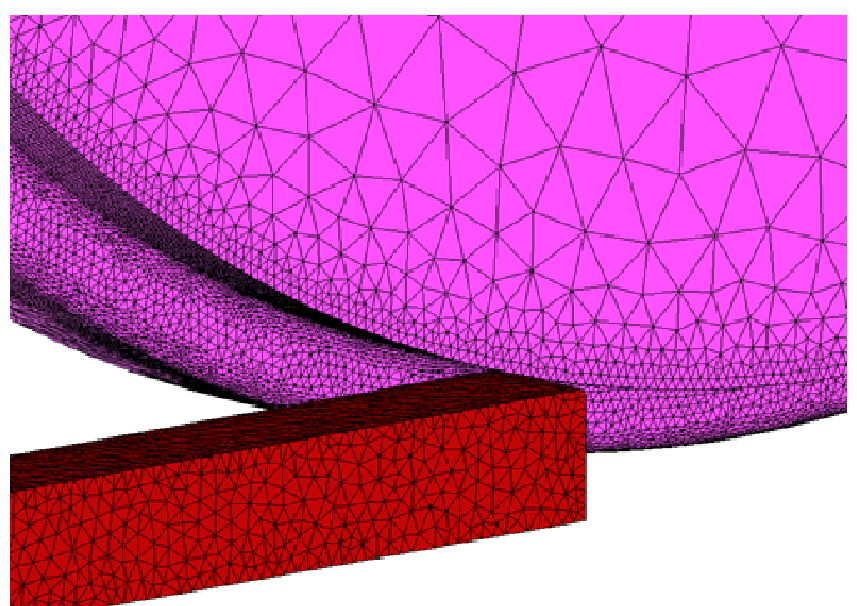

Fig. 1. View of the roll and the mesh in the FE model

Flow stress in the constitutive model was described by the Sellars-Teggart equation [6]. Coefficients in this equation were determined by inverse analysis of plastometric tests. 
Microstructure evolution. Microstructure evolution model describing static and dynamic recrystallization as well as grain growth was based on fundamental works of Sellars [7]. Coefficients in this model were determined on the basis of stress relaxation tests performed for the investigated steel.

Phase transformations. Modelling of phase transformation was based on Johnson, Mehl, Avrami Kolmogorov (JMAK) equation:

$$
X=1-\exp \left(-k t^{n}\right)
$$

where: $X$-volume fraction of a new phase, $t$ - time, $k, n$ - coefficients.

Full descriptions of the model including all phase transformations is presented in [8]. Coefficients in this model were obtained using inverse analysis of dilatometric tests and are given in this publication, as well.

Very short computing time is an advantage of the model. Phase transformations can be simulated at each Gauss point of the FE mesh without significant increase of the computing time. On the other hand, capability to monitor changes of the carbon concentration in the austenite and, in consequence, capability to predict occurrence of the retained austenite, is the main advantage of this simple model.

Modelling of the retained austenite during transformations is a complex problem. Two theories of the kinetics (mechanism) of the bainite transformation were proposed in the literature. The first is reconstructive mechanism [9], which considers that bainite is a non-lamellar two-phase aggregate of ferrite and carbides. The second is displacive theory [10], according to which the formation of bainite causes a deformation with a larger shear and a dilatational strain normal to the habit plane. Bainite nucleation is considered to occur by the spontaneous dissociation of specific dislocation defects, which are already present in the parent phase. The concept of nucleation and growth of bainitic ferrite platelets was employed in this mechanism. Review of displacive models for bainite transformation was presented in [11]. Semi-empirical model of displacive transformation was proposed in [12] and applied to predict the retained austenite volume fraction in TRIP steels.

Two versions of the model were considered in [8]. The first corresponds to the reconstructive mechanism of transformation and it is based on the typical JMAK approach. It assumes that carbon concentration in the austenite does not change during the bainite transformation. This is a commonly made assumption, see earlier Authors publication [13], which leads to a situation that martensite start temperature does not change noticeably for various cooling rates. This change is only due to the increase of the carbon concentration $\left(c_{\gamma}\right)$ in austenite during the ferritic transformation:

$c_{\gamma}=\frac{\left(c_{0}-F_{f} c_{\alpha}\right)}{1-F_{f}}$

where: $F_{f}$ - ferrite volume fraction, $c_{0}, c_{\alpha}$ - carbon concentration in steel and in ferrite, respectively.

The second version of the model corresponds to the displacive mechanism of transformation and accounts for carbon concentration changes in the austenite during bainite transformation. It is assumed that every individual bainitic ferrite platelet initially inherits the parent phase composition (is supersaturated with carbon). As soon as it forms, the platelet begins to reject the excess carbon to the austenite in a thicknesswise manner $[12,14]$. The carbon rejected by a single platelet leads to a transient concentration gradient in the austenite. The character of this gradient depends on the relative dimension of platelet thickness $\left(w_{\alpha B}\right)$ and thickness of the adjacent austenite layer $\left(w_{\gamma}\right)$. Size of the platelet depends on the transformation temperature, following the empirical equation [15]:

$$
w_{\alpha B}=\left(0.478+1.2 T+1.25 T \Delta G^{\gamma \rightarrow \alpha}-22 \sigma_{\gamma}\right) \times 10^{-4}
$$

where: $\Delta G^{\gamma \rightarrow \alpha}$ - the driving force for ferrite nucleation, $\sigma_{\gamma}$ - strength of the austenite in MPa given by a function of the temperature: 


$$
\begin{aligned}
& \sigma_{\gamma}=1-2.6 \times 10^{-3} \bar{T}+0.47 \times 10^{-5} \bar{T}^{2}+0.326 \times 10^{-8} \bar{T}^{3}+15.4\left[\mathrm{C}_{e}\right] \\
& \bar{T}=T-25 \\
& \mathrm{C}_{e}=3.6+23[\mathrm{C}]+1.3[\mathrm{Si}]+0.65[\mathrm{Mn}]
\end{aligned}
$$

The temperature is in ${ }^{\circ} \mathrm{C}$ and the concentrations are in $w t \%$. Thickness of the adjacent austenite layer $\left(w_{\gamma}\right)$ depends on the previously formed bainitic ferrite platelets. Following [12] two possibilities were considered:

- A platelet forms in a close neighbourhood of the existing one and its diffusion field is constrained by this neighbour. If the thickness of the intervening austenite layer is smaller than a certain critical value, the carbon trapped between the two platelets cannot be distributed and this part of the austenite is stabilized. This critical size of the austenite layer $\left(w_{\gamma c r}\right)$ is calculated from the mass balance:

$$
w_{\gamma c r}=\frac{w_{\alpha B} c_{0}}{2\left(c_{M}-c_{0}\right)}
$$

where: $c_{M}$ - carbon concentration calculated assuming martensite start temperature equal to room temperature [8].

- A platelet forms in an unconstrained area, which is free of already existing platelets. In this case, the carbon rejected by the platelet is free to diffuse far inside the adjacent austenite layer.

Following [12] an assumption was made that the first option occurs with certain probability $p$ and the second with the probability $(1-p)$. If the first option is valid, the whole volume of the austenite layer is stabilized and it contributes to the volume fraction of the retained austenite $F_{a 0}$. If the second option is valid, the carbon homogenization by diffusion is simulated. In practical solution for investigated group of steels $p$ is below 0.2 .

As soon as the carbon rejection begins, its concentration in the austenite at the interface reaches the value calculated from the $T_{0}$ temperature concept [16]. The $T_{0}$ curve is the locus of points on the temperature vs. carbon concentration plot where austenite and ferrite of the same chemical composition have identical free energies. This concentration is a boundary condition for calculation of the carbon distribution in the austenite using the diffusion model. At some stage in the evolution of the microstructure the austenite carbon concentration reaches the $T_{0}$ curve at which point bainite ceases to form assuming a homogeneous distribution of carbon in the austenite. The reaction is said to be incomplete since it stops before the austenite has achieved composition given by the $T_{0}$ curve prior to reaching the equilibrium composition. Naturally, it is at this stage that the retained austenite is most stabilized by carbon, which has reached its maximum permissible concentration in the context of bainite. The incomplete transformation leaves films of austenite between bainite plates.

The main feature of the model [8] comparing to the conventional approach [13] is connected with the bainite transformation. Beyond the bainitic ferrite volume fraction, thickness of the platelets is calculated using equation (3). The relative platelet thickness is introduced as $\underline{w}_{\alpha B}=$ $w_{\alpha B} / D_{\gamma}$, where $D_{\gamma}$ is the austenite grain size. Similarly, the relative critical size of the austenite layer is introduced as $\underline{w}_{\gamma c r}=w_{\gamma c r} / D_{\gamma}$. Following described above concept of the two platelets types, it can be stated that $p F_{b}$ volume fraction of bainite traps volume fraction $F_{a 0}=p F_{b} w_{\gamma c r} / w_{\gamma B}$ of austenite, which is stabilized and becomes retained austenite. Carbon diffusion is simulated in the remaining part of the austenite $\left(1-F_{a 0}\right)$. The current average carbon content in this part of the austenite during the bainitic transformation $\left(c_{\gamma}\right)$ is described by the equation:

$$
c_{\gamma}=\frac{1}{1-F_{f}-\frac{F_{b}}{1-p}}\left[c_{0}-\left(F_{f}+\frac{F_{b}}{1-p}\right) c_{\alpha}\right]
$$

where: $F_{f}$ - volume fraction of ferrite, $c_{0}$ - carbon concentration in steel, $c_{\alpha}-$ carbon concentration in ferrite. 
Modelling of the bainite transformations starts with equation (1) when the temperature drops below bainite start $B_{s}$ [8]. The Scheil additivity rule is applied in the model to account for the temperature variations during transformation. The transformed bainite volume fraction $X_{b}(T)$ is calculated from equation (1) with respect to the maximum volume fraction of bainite $F_{b \max }(T)$ for the current temperature $T$, which is determined by the $T_{0}$ line:

$$
F_{b \max }=\frac{c_{T 0}-c_{0}}{c_{T 0}-c_{\alpha}}
$$

where: $c_{T 0}$ - carbon concentration calculated from the $T_{0}$ line for the current temperature.

Thus, the volume fraction of bainite with respect to the whole volume of the material is $F_{b}=F_{b \max } X_{b}\left(1-F_{f}-F_{p}-F_{m}\right)$ for the fixed temperature $T$, where $F_{f}, F_{p}, F_{m}$, - volume fractions of ferrite, pearlite and martensite, respectively. The value of $X_{b}$ calculated from equation (1) for the varying temperature has to be corrected due to the change of the equilibrium (maximum) bainite volume fraction $F_{b \max }$, which according to equations $(8)$ is the temperature function. The correction is made as follows:

$$
X_{b}\left(T_{i+1}\right)=X_{b}\left(T_{i}\right) \frac{F_{b \max }\left(T_{i}\right)}{F_{b \max }\left(T_{i+1}\right)}
$$

where: $i$-iteration number, $T_{i}-$ temperature in $i^{\text {th }}$ iteration.

The simulation continues until one of the following conditions is fulfilled:

- the transformed volume fraction achieves 1 , or

- the temperature drops below $M_{s}$ calculated for $c_{\gamma}$ determined by equation (7), or

- $c_{\gamma}$ from equation (7) achieves $c_{T 0}$.

In consequence, the effect of carbon segregation during the bainite transformation on the $M_{s}$ temperature is accounted for in calculations. This feature of the model allows prediction of the retained austenite occurrence in steel.

Concentration $c_{\gamma}$ determined by equation (7) is an average for the austenite remaining during bainite transformation excluding that trapped between closely located bainitic ferrite platelets. It means that when the temperature drops to the room temperature $T_{r}$, this austenite can either remain as the retained austenite (if $M_{s}<T_{r}$ ) or can be partly transformed into the martensite according to the Koistinen-Marburger equation [17] (if $M_{s}>T_{r}$ ). In the physical transformation both martensite and retained austenite may occur. To implement this functionality in the model, the carbon distribution in the austenite was accounted for. The assumption of exponential distribution along the distance from the interface $x$, assuming concentration $c_{T 0}$ at the interface and average concentration $c_{\gamma}$ in the austenite, was used:

$$
\begin{aligned}
& c(x)=A \exp (-B x)+c_{0} \\
& c(0)=c_{T 0} \Rightarrow A=c_{T 0}-c_{0} \\
& \int_{0}^{\frac{1}{2} \underline{w}_{\gamma}}\left(c_{T 0}-c_{0}\right) \exp (-B x) d x=c_{\gamma}
\end{aligned}
$$

where: $\underline{w}_{\gamma}$ - the relative average distance between platelets of the bainitic ferrite, calculated as:

$$
\underline{w}_{\gamma}=\frac{\underline{w}_{\alpha B}\left(1-F_{b}\right)}{(1-p) F_{b}}
$$


Details of this solution are given in [8]. When the temperature drops to the room temperature, the austenite volume fraction $\left(X_{a 1}\right)$ is calculated from equation $(10)$ :

$$
X_{a 1}=\frac{-1}{B} \ln \left[\frac{1}{A}\left(c_{M}-c_{0}\right)\right]
$$

The total volume fraction of the retained austenite is the sum of that contributed by the austenite trapped between closely located platelets of the bainitic ferrite $X_{a 0}$ and that resulting from the carbon concentration inhomogeneity in remaining layers of the austenite $X_{a 1}$. Finally, the volume fraction of the austenite with respect to the whole volume of the materials is calculated as:

$$
F_{a}=\left(1-F_{f}-F_{p}-F_{m}\right)\left(X_{a 0}+X_{a 1}\right)
$$

The proposed model is very fast and it allows to calculate volume fractions of phases, including retained austenite, after various thermal cycles during cooling of hot rolled rods. In consequence, fast simulation of thermal, mechanical and microstructural phenomena became possible.

\section{Results}

Simulation of the whole manufacturing cycle composed of hot rolling and controlled cooling was performed and selected results are presented in this section.

Validation. Thermal model only was validated in the present work. Measured and calculated temperatures during cooling of the rod in the air are shown in Figure 2. Measurements were performed by the thermocouples inserted in the rod, which was heated in the furnace to $940{ }^{\circ} \mathrm{C}$. Results for three points at the cross section are shown: $\mathrm{A}$ - corner, $\mathrm{B}$ - centre of the side, $\mathrm{C}$ - centre of the rod. It is seen that reasonably good agreement between calculations and measurements was obtained and that the model predicts properly heat generated due to bainitic transformation.

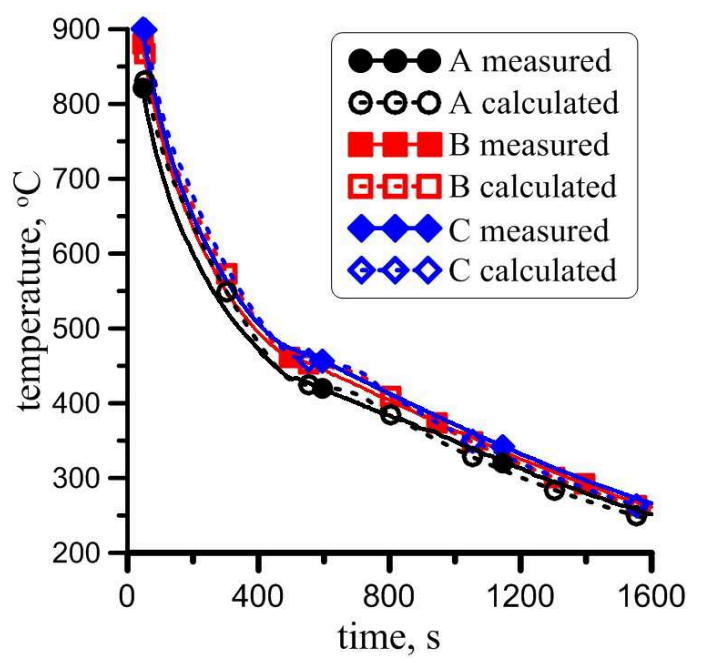

Fig. 2. Comparison of measured and calculated temperatures during cooling of the rod in the air.

Rolling. Calculations started with temperature changes and grain growth during transport of the rod from the furnace to the rolling mill and the results are shown in Figure 3. Figure 4 shows a situation in the first pass. It is seen that strain after exit is reduced due to static recrystallization (SRX). This effect is also observed for the grain size. New grains measuring about $55 \mu \mathrm{m}$ are created. Similar results for the second pass are shown in Figure 5. Due to the contact between the rod and the roll a temperature drop by $5-6^{\circ} \mathrm{C}$ is observed, nevertheless, due to deformation heating the temperature at the centre of the rod increases by about $10-11^{\circ} \mathrm{C}$. Grain size after the SRX after the second pass is shown in Figure 6a. Grain refinement to $25-35 \mu \mathrm{m}$ was predicted. During further cooling in the air the grain growth to $38-45 \mu \mathrm{m}$ was obtained (Figure $6 \mathrm{~b}$ ). 


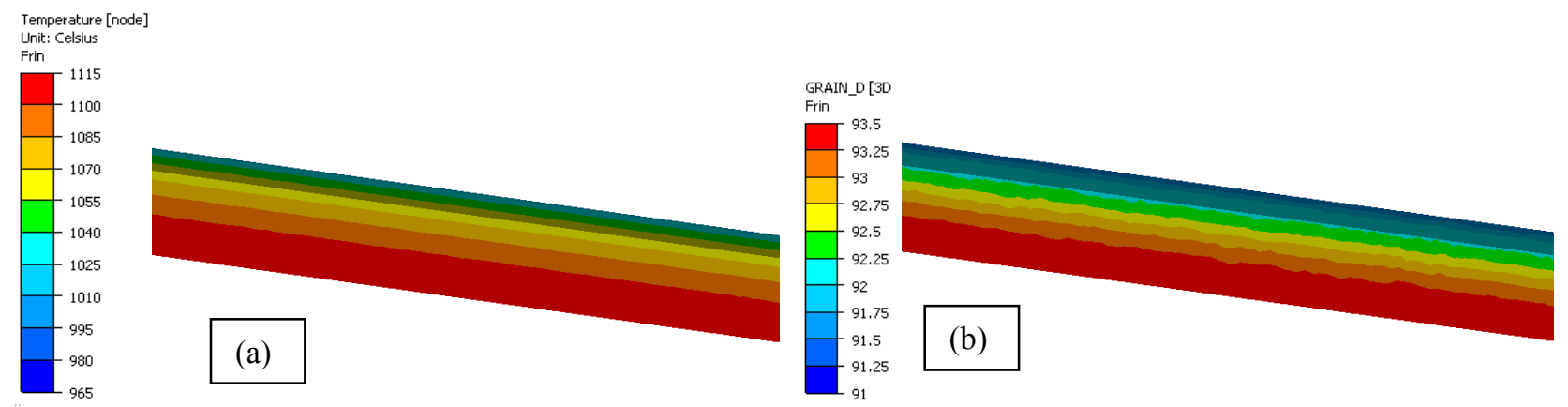

Fig. 3. Calculated temperatures (a) and grain size (b) in the rod at the entry to the $1^{\text {st }}$ rolling pass.
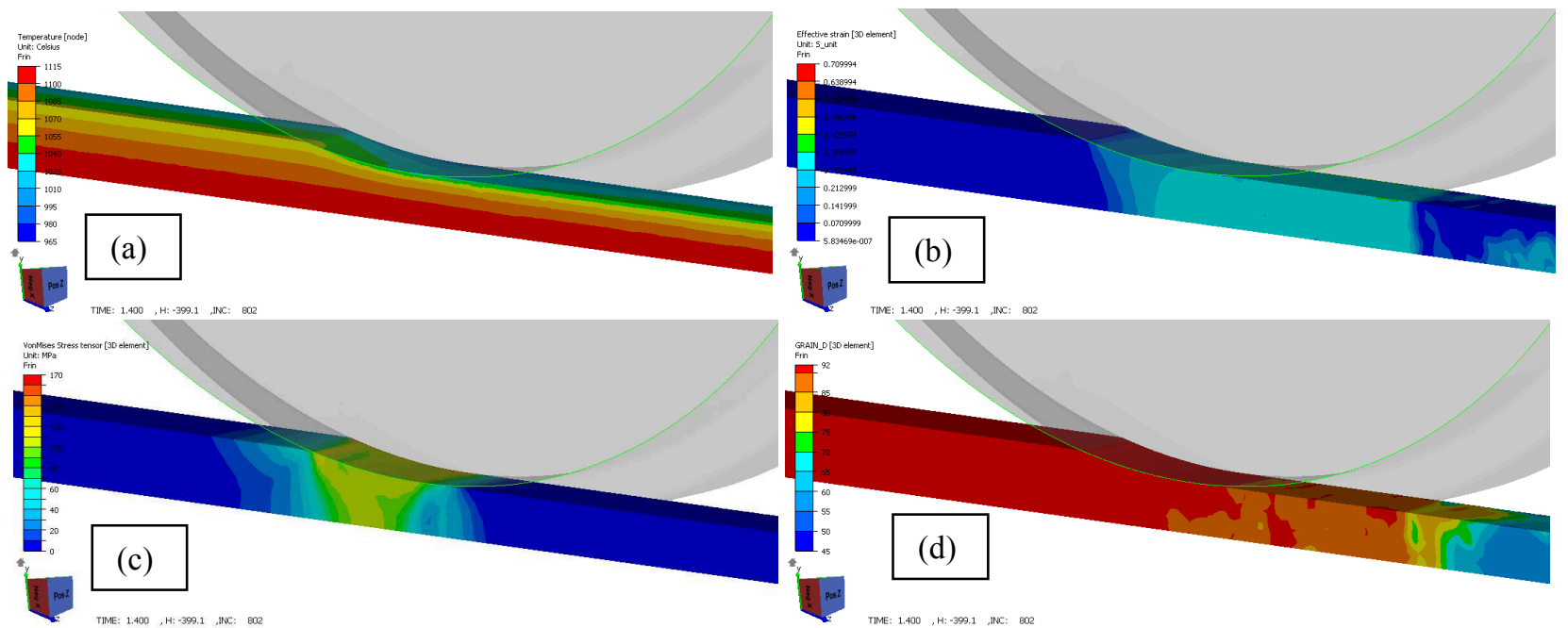

Fig. 4. Calculated temperatures (a), effective strains (b) effective stresses (c) and grain size (d) in the rod during the $1^{\text {st }}$ rolling pass.

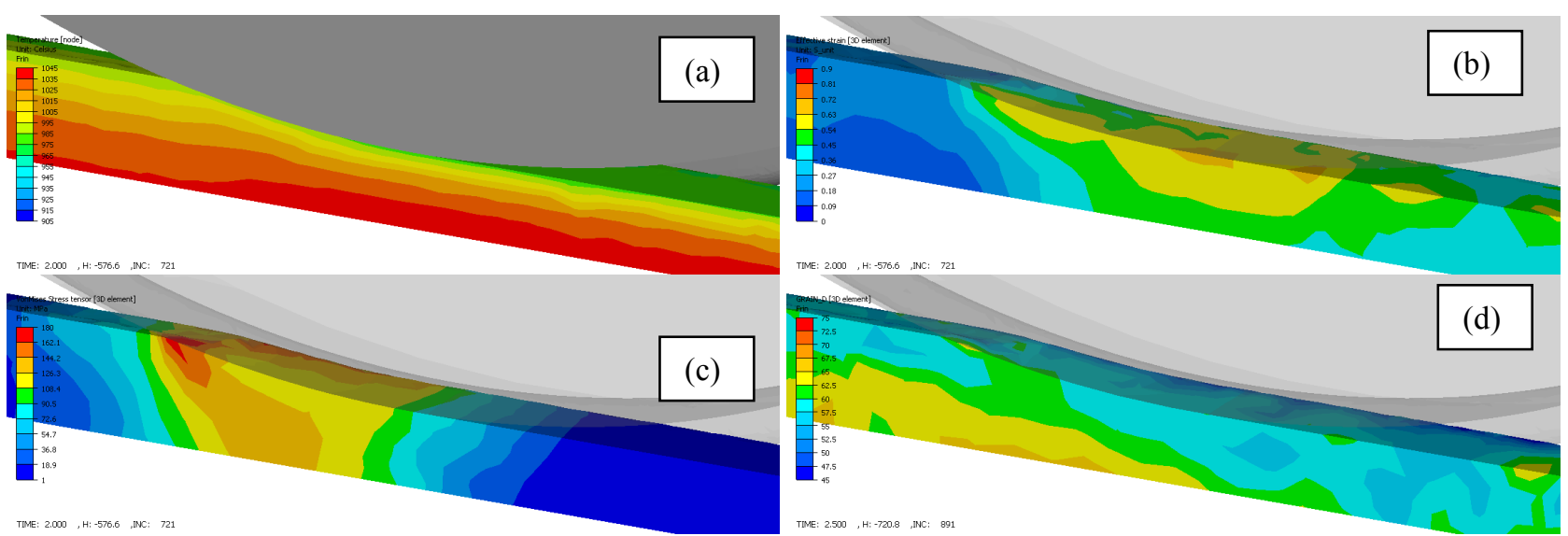

Fig. 5. Calculated temperatures (a), effective strains (b) effective stresses (c) and grain size (d) in the rod during the $2^{\text {nd }}$ rolling pass.

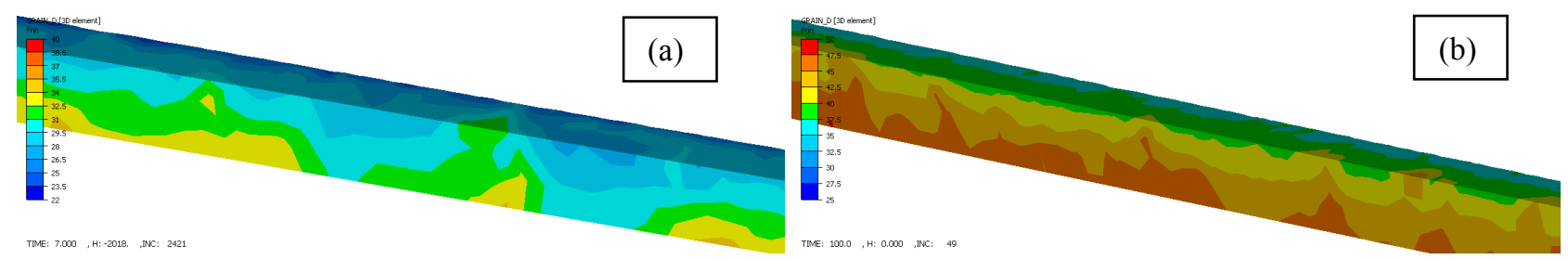

Fig. 6. Calculated grain size after the $2^{\text {nd }}$ pass (a) and after $100 \mathrm{~s}$ of cooling in the air (b). 
Cooling. During air cooling after rolling, grain growth to about $38-45 \mu \mathrm{m}$ was obtained (Figure 6b). This grain size distribution, as well as temperature distribution after cooling, were used as a starting point for the simulations of phase transformations. The model based on JMAK equation and described in [13], combined with equations (2)- (14) in the present paper, was used in simulations. Figure $7 \mathrm{a}, \mathrm{b}, \mathrm{c}$ show calculated transformation kinetics at three investigated points. Some ferrite (about $10 \%$ ) occurs at the beginning of cooling but bainite is a dominant phase in the final product.

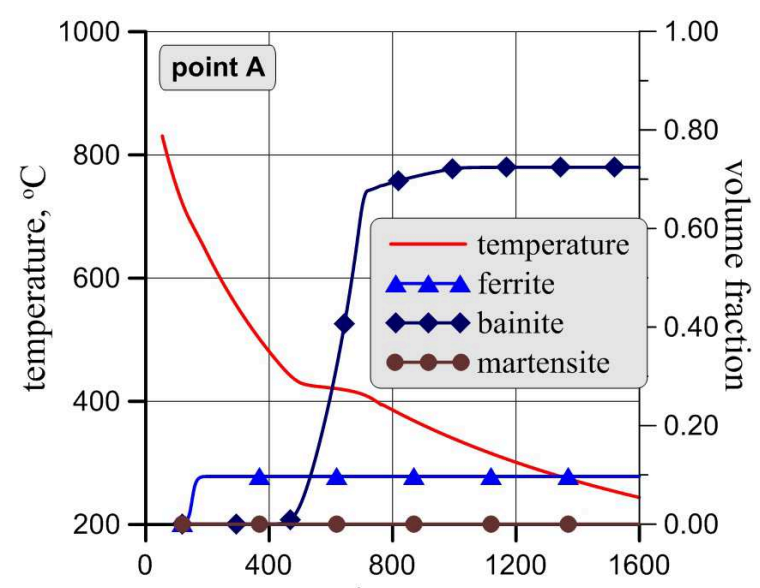

a)

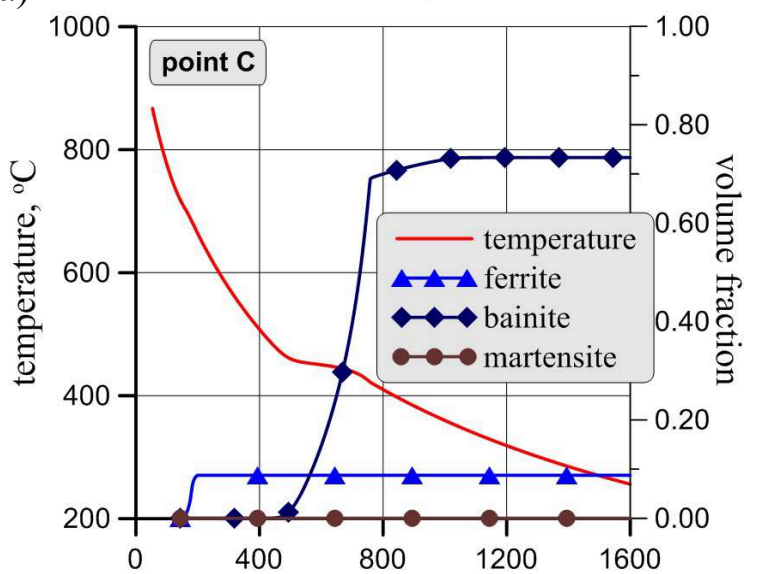

c)

time, $s$

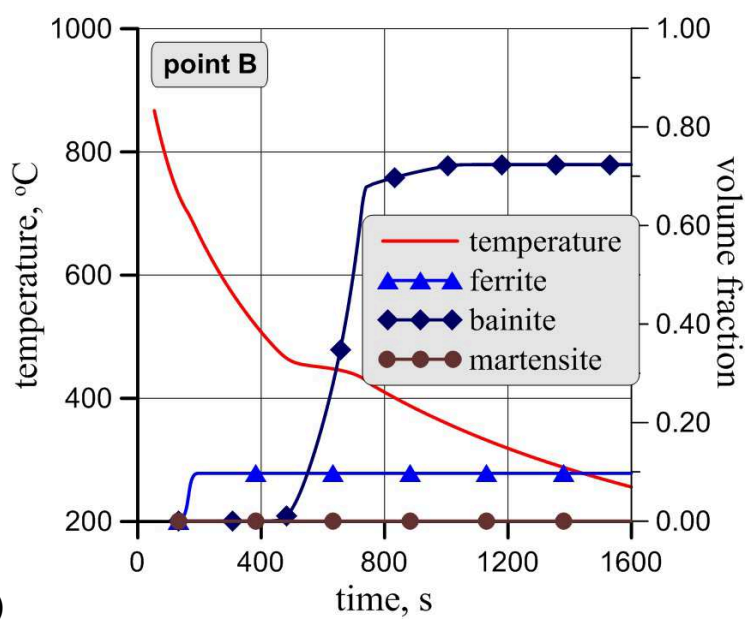

b)

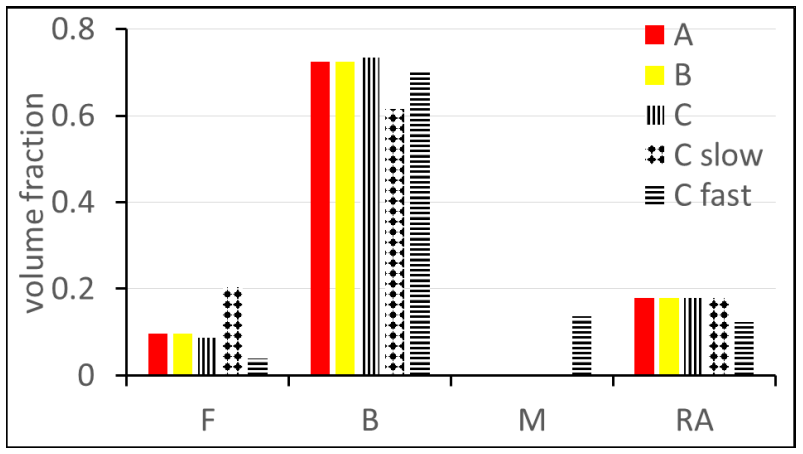

Fig. 7. Kinetics of transformations calculated at three investigated points (a-c) and volume fractions of phases at these points $(\mathrm{d})$.

It is seen in Figure 7a,b,c that differences between points $\mathrm{A}, \mathrm{B}$ and $\mathrm{C}$ are small. This observation is confirmed by Figure $7 \mathrm{~d}$ where phase volume fractions of at these points are shown. Calculated distribution of the retained austenite at the cross section of the rod is uniform at the level of $18 \%$. Mechanism of occurrence of the retained austenite is explained in Figure 8 where changes of the average carbon concentration in austenite during cooling are shown. Due to the displacive character of bainite transformation carbon concentration in the austenite during this transformation increases and reaches the level at which martensite start temperature drops below the room temperature.

To demonstrate capabilities of the model calculation for the decreased and increased cooling rate were performed. These results are shown in Figure $7 \mathrm{~d}$ as $\mathrm{C}_{-}$slow and $\mathrm{C}$ fast, respectively. Cooling rates between $600{ }^{\circ} \mathrm{C}$ and $B_{s}$ for these two cases were $0.3{ }^{\circ} \mathrm{C} / \mathrm{s}$ and $1.6^{\circ} \mathrm{C} / \mathrm{s}$, respectively. Kinetics of transformations for slower and faster cooling are shown in Figure 9. It is seen in these figures that slight decrease of the cooling rate leads to an increase of ferrite and decrease of bainite volume fractions, while the retained austenite volume fraction does not change noticeably. Contrary, slight increase of the cooling rate leads to an increase of bainite and martensite volume fractions and retained austenite volume fraction decreases. 


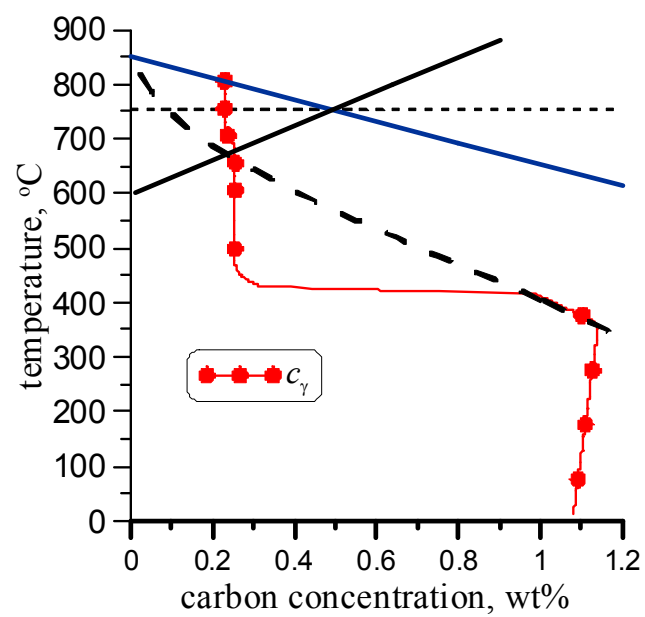

Fig. 8. Changes of the average carbon concentration in austenite $\left(c_{\gamma}\right)$ during cooling.
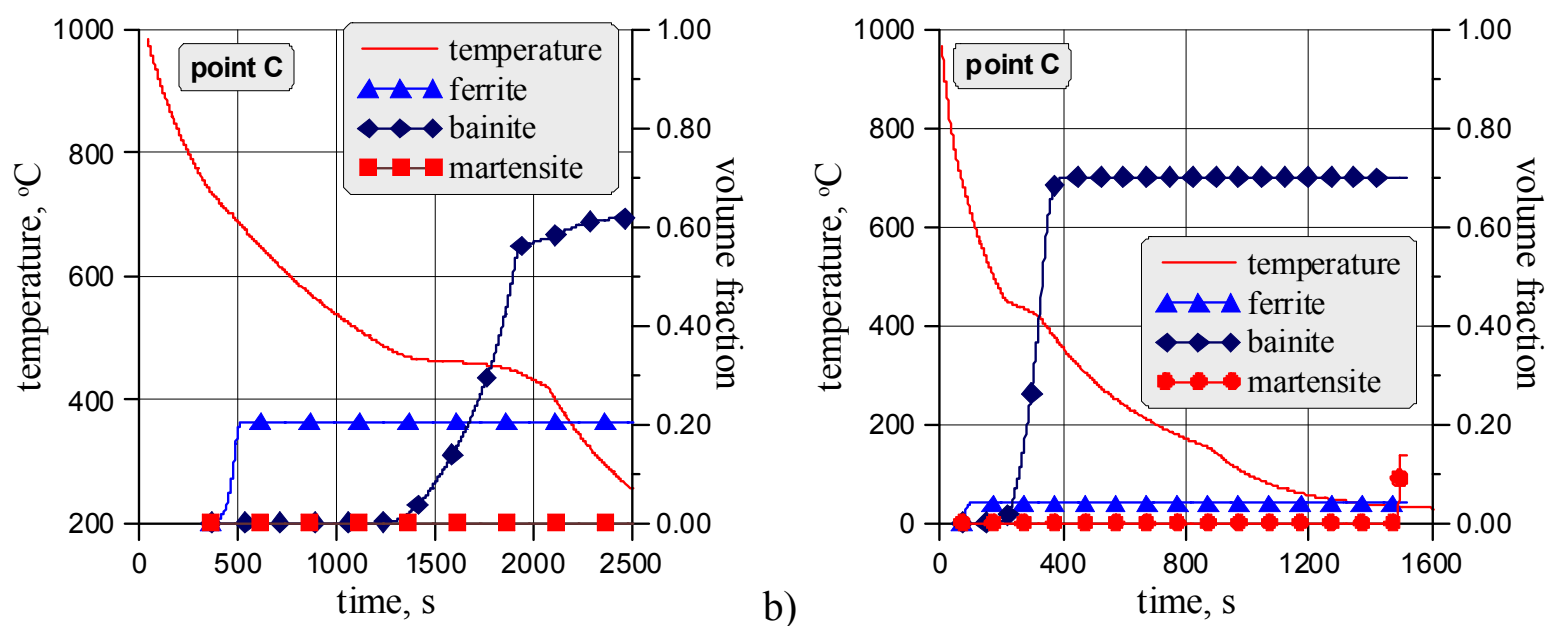

b)

time, $\mathrm{s}$

Fig. 9. Kinetics of phase transformations at the centre of the rod cross section calculated for a decreased (a) and increased (b) cooling rate.

Microstructures at the cross section of the rod taken close to the edge and in the centre of the rod are presented in Figure 10. Roentgen micro-diffraction method was used to obtain these micrographs. Pictures with three different magnifications are shown in this figure. Measurements of the retained austenite volume fraction gave the results of $16.8 \pm 0.8 \%$ close to the edge and $14.2 \pm$ $0.7 \%$ in the centre of the cross section. These values agree reasonably well with the predictions of the model shown in Figure $7 \mathrm{~d}$.

\section{Conclusions}

Numerical simulation of the manufacturing cycle composed of hot rolling and controlled cooling of rods was performed and the results were compared with physical simulations of cooling. The following conclusions were drawn:

- Microstructure evolution model based on [6] implemented in the thermal-mechanical FE program allowed to predict temperature distribution and grain size distribution at the beginning of phase transformations.

- Experimental verification confirmed good accuracy of the thermal model including prediction of heat generated due to transformations.

- Modified JMAK model combined with equations describing average carbon concentration in the austenite during bainitic transformation allowed to predict occurrence of the retained austenite.

- Cooling of bainitic steel rods in the air resulted in the about $18 \%$ of retained austenite. Distribution of the retained austenite at the rod cross section was reasonably uniform. 


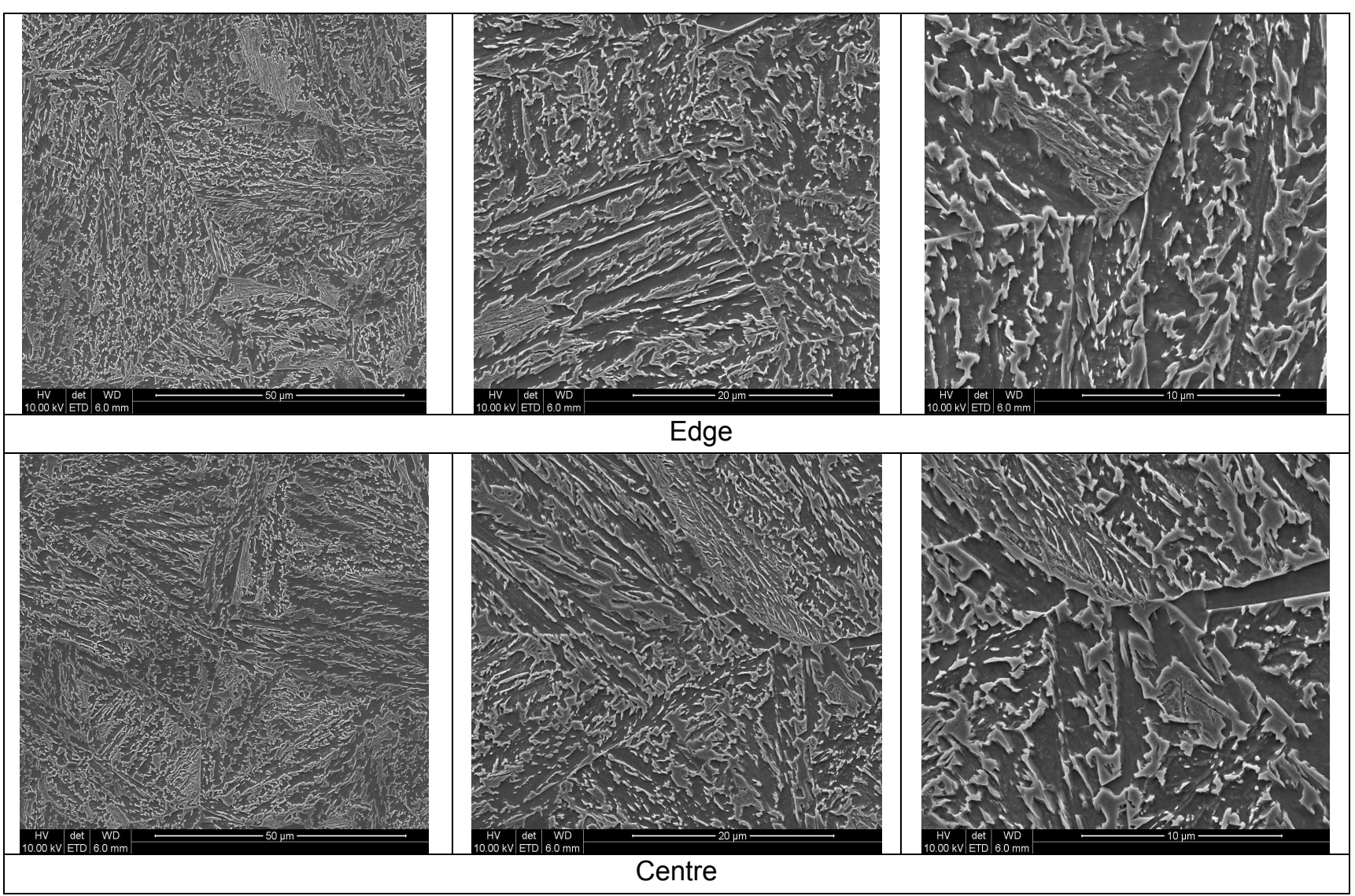

Fig. 10. Microstructures at the cross section of the rod taken close to the edge (top) and at the centre (bottom).

- Good accuracy of the model was confirmed by comparison of the calculated and measured retained austenite volume fraction at the cross section of the rods after cooling.

- Accelerated cooling leads to the occurrence of martensite and to a decrease of the retained austenite volume fraction.

\section{Acknowledgements}

Work within the AGH project 11.11.110.291 is acknowledged. The support of Swiss Steel within the project "Development of new high-strength complex-phases steels" is acknowledged, as well.

\section{References}

[1] H. K. D. H. Bhadeshia, Bainite in steels, The Inst. of Mater., London, 1991.

[2] H. K. D. H. Bhadeshia, High performance bainitic steels, Materials Science Forum 500-501 (2005) 63-74.

[3] K. M. Lee, A. A. Polycarpou, Wear of conventional pearlitic and improved bainitic rail steels, Wear 259 (2005) 391-399.

[4] S. Waengler, R. Kawalla, R. Kuziak, High strength-high toughness bainitic steels alloyed with niobium for long products, steel research international 79 (2008) spec. ed. Metal Forming Conf., 2, 273-279.

[5] Ł. Rauch, R. Kuziak, M. Pietrzyk, From high accuracy to high efficiency in simulations of processing of dual-phase steels, Metallurgical and Materials Transactions B 45 (2014) 497-506.

[6] C. M. Sellars, G. McTeggart, Hot workability, International Metals Reviews 17 (1972) 1-24. 
[7] C. M. Sellars, Physical metallurgy of hot working, in: Hot Working and Forming Processes, Eds, C. M. Sellars, G. J. Davies, The Metals Society, London, 1979, 3-15.

[8] M. Pietrzyk, Z. Kania, R. Kuziak, Ł. Rauch, J. Kusiak, A simple model for prediction of retained austenite in steel rods after hot rolling and controlled cooling, Proc. XXXV Verformungskundliches Kolloquium, Ed., B. Buchmayr, Zauchensee, 2016, 56-66.

[9] H. I. Aaronson, The decomposition of the austenite by diffusional processes, Eds, V. F. Zackary, H. I. Aaronson, Interscience Publishers, New York, 1962, 387-546.

[10]H. K. D. H. Bhadeshia, D. V. Edmonds, The mechanism of bainite formation in steels, Acta Metallurgica 28 (1980) 1265-1273.

[11]M. J. Santofimia, F. G. Caballero, C. Capdevila, C. Garcia-Meteo, C. G. de Andres, Evaluation of displacive models for bainite transformation kinetics in steels, Materials Transactions 47 (2006) 1492-1500.

[12]A. I. Katsamas, G. N. Haidemenopoulos, A semi-empirical model for the evolution of retained austenite via bainitic transformation in multiphase TRIP steels, Steel Research International 79 (2008) 875-884.

[13]M. Pietrzyk, R. Kuziak, Modelling phase transformations in steel, in: Microstructure evolution in metal forming processes, Eds, J. Lin, D. Balint, M. Pietrzyk, Woodhead Publishing, Oxford, 2012, 145-179.

[14]M. Hillert, L. Hoglund, J. Agren, Escape of carbon from ferrite plates in austenite, Acta Metallurgica et Materialia 41 (1993) 1951-1957.

[15]M. Azuma, N. Fujita, M. Takahashi, T. Senuma, D. Quidort, T. Lung: Modelling upper and lower bainite transformations in steels, ISIJ International 45 (2005) 221-228.

[16]H. K. D. H. Bhadeshia, The Lower bainite transformation and the significance of carbide precipitation, Acta Metallurgica 28 (1980) 1103-1114.

[17]D. P. Koistinen, R. E. Marburger, A general equation prescribing the extent of the austenitemartensite transformation in pure iron-carbon alloys and plain carbon steels, Acta Metallurgica 7 (1959) 59-69. 